\title{
Bone Cement Implantation Syndrome ( BCIS ) - A Case Report
}

\author{
Anish.K.A ${ }^{1}$, Suranjith.Sorake ${ }^{2}$, S.Padmanabha ${ }^{3}$ \\ ${ }^{1,2,3}$ Yenepoya Medical College, Yenepoya University, Deralakatte, Mangalore-575018, India.
}

\begin{abstract}
A 51 year old male was admitted in our hospital with fracture neck of right femur and posted for bipolar hemiarthroplasty. Spinal anaesthesia was given in $L_{2} L_{3}$ space using $3.5 \mathrm{ml} 0.5 \%$ bupivacaine heavy with $25 m c g$ fentanyl, with $25 \mathrm{G}$ quincke needle. During application of the high viscosity gentamycin bone cement, patient developed severe hypotension, bradycardia, hypoxia and cardiac arrest. High quality CPR started immediately, patient intubated and intravenous adrenaline $1 \mathrm{mg}$ given. After successful resuscitation surgery continued under general anaesthesia. Patient was post operatively ventilated and monitored in surgical ICU for next 6 hours and he made a full recovery.
\end{abstract}

Keywords : Bipolar hemiarthroplasty, spinal anaesthesia, high viscosity gentamycin bone cement, cardiac arrest.

\section{INTRODUCTION}

Bone Cement Implantation Syndrome (BCIS) is a rare complication of bone cementation used in orthopaedic procedures. Clinical features include hypotension, bradycardia, hypoxia and even cardiac arrest. Early diagnosis is crucial in determining the outcome of BCIS. Management is mainly supportive along Basic Life Support (BLS) and Advanced Cardiovascular Life Support (ACLS) guidelines.

\section{Case History}

A 51 year old male was admitted in our hospital with a history of road traffic accident of 1day duration. Patient complained of pain and tenderness in the right hip and difficulty in walking. He is a known alcoholic and smoker and had a history of pulmonary tuberculosis 16 years ago and had taken a complete one year course of medication and achieved remission. Radiographic examination revealed a comminuted fracture of neck of right femur extending into the lesser tubercle. The patient was posted for bipolar hemiarthroplasty the next day.

\section{Anaesthetic Management}

After a detailed pre anaesthetic evaluation and investigations, written informed consent was obtained from the patient. He was kept nil per orally 6 hours for solids and 12 hours for clear fluids. Tab Ranitidine 150mg and Tab Lorazepam $1 \mathrm{mg}$ was given orally as premedication. Venous access secured by an $18 \mathrm{G}$ intravenous cannula on the dorsum of the left hand and patient preloaded with $500 \mathrm{ml}$ Ringer Lactate solution. Spinal anaesthesia was administered with a $25 \mathrm{G}$ quincke needle in $\mathrm{L}_{2} \mathrm{~L}_{3}$ space in sitting position. $3.5 \mathrm{ml}$ of $0.5 \%$ bupivacaine heavy and $25 \mathrm{mcg}$ of fentanyl was given intrathecally. After 10mins patient was put in left lateral position. $\mathrm{T}_{5} \mathrm{~T}_{6}$ block was achieved and the episode of hypotension was treated successfully with $6 \mathrm{mg}$ mephentermine.

One and half hours into the surgery during reaming of the medullary cavity there was a hairline fracture extending into the mid shaft of femur. Thus it was decided to attach the implant with bone cement. DePuy high viscosity gentamycin cement was inserted into medullary cavity digitally and $49 \mathrm{~mm}$ stainless steel bipolar hip prosthesis placed in position. One minute after cement application there was severe bradycardia and hypotension. Inspite of intravenous atropine $0.6 \mathrm{mg}$ there was no response. And further there was severe hypotension and carotids were not felt. Saturation dropped to $78 \%$ and patient became unconscious and diagnosis of cardiac arrest was made.

The surgical site was immediately packed and patient shifted to supine position. Chest compressions were started and patient was intubated with No 8 internal diameter cuffed endotracheal tube and ventilated with $100 \%$ oxygen. Intravenous adrenaline $1 \mathrm{mg}$ in $10 \mathrm{ml}$ saline was given. Fluids were rushed and dopamine $10 \mathrm{mcg} / \mathrm{kg} / \mathrm{min}$ started. Cardiac compressions continued. After 2 cycles of high quality CPR, bradycardia and hypotension resolved and patient's conscious level improved. Inj Atracurium $0.5 \mathrm{mg} / \mathrm{kg}$ intravenous was given and surgery continued. Anaesthesia was maintained with 50:50 oxygen:nitrous oxide and controlled ventilation. Rest of surgery went uneventfully.

Patient was shifted to surgical ICU and connected to ventilator and post intubation measures were taken using dexamethasone, furosemide and mannitol to maintain urine output at $0.5 \mathrm{ml} / \mathrm{kg} / \mathrm{hr}$. After overnight ventilator support, weaning was done and he recovered without any central nervous effects. Post operative arterial blood gas analysis, chest X-ray and blood investigations remained normal. Patient was discharged from surgical ICU on third post operative day and discharged home on tenth day. 


\section{Discussion}

Poly methyl methacrylate (PMMA) bone cement is nowadays used in a wide variety of orthopaedic procedures like hip arthroplasty. The bone cement is constituted by mixing a liquid component (containing methyl methacrylate and a activator like N,N-dimethyl-p-toluidine) with a powder component (containing PMMA, a initiator like benzoyl peroxide and antibiotics like gentamycin) the constituted bone cement rely on mechanical interlocking between irregular bone surfaces and the prosthesis.

Bone Cement Implantation syndrome (BCIS) is a rare and under reported complication of cemented orthopaedic surgeries. BCIS is characterized by hypoxia, hypotension or both and/or unexpected loss of consciousness occurring around the time of cementation, prosthesis insertion, reduction of the joint or, occasionally, limb tourniquet deflation in a patient undergoing cemented bone surgery[2]. Other complications include pulmonary hypertension[14],pulmonary edema[14], bronchoconstriction[14], cardiac dysarrythmia[15], cardiac arrest[15], hypothermia[15] and thrombocytopenia[15] The true incidence of cardiac arrest secondary to BCIS is unknown, and mortality data are not systematically collected or published[2]. Some of the proposed causes of BCIS include toxic effects of systemically absorbed methyl methacrylate[11], high intramedullary pressures due to pressurizing effect of bone cement or reaming[11], fat embolism[12], release of endogenous vasodilatory cannabinoids[13].

Constant monitoring and a high degree of suspicion during and after bone cementation is vital in early diagnosis and management of BCIS. Management includes administration of $100 \%$ oxygen with control of airway, invasive hemodynamic monitoring, aggressive fluid therapy, use of vasopressors if required[16]. Surgical procedures to minimize excessive cement pressurisation[16] and the use of low toxicity monomeric bone cement[7] is very helpful in preventing BCIS to a large extent.

\section{Conclusion}

BCIS is a rare complication of bone cementation in orthopaedic procedures. Constant monitoring and early diagnosis during and after bone cementation plays a pivotal role in reducing patient morbidity and mortality. Common presentation of BCIS include hypotension, hypoxemia, unconsciousness and even cardiac arrest. Management include supportive measures along BLS and ACLS guidelines.

\section{REFERENCES}

\section{Journal Papers:}

[1] Stavros G. Memtsoudis, Eduardo A. Salvati, George Go, Yan Ma, Nigel E. Sharrock. Perioperative Pulmonary Circulatory Changes During Bilateral Total Hip Arthroplasty Under Regional Anesthesia. Regional Anesthesia and Pain Medicine. 2010;35(5):417-421

[2] A.J.Donaldson, H.E.Thomson, N.J.Harper, N.W.Kenny. Bone Cement Implantation Syndrome. British Journal of Anaesthesia. 2009;102(1):12-22

[3] Pradeep Govil, P N Kakar, Deep Arora, Shibani Das, Nishkarsh Gupta, Deepak Govil, Sachin Gupta, Ashima Malohtra, Bone Cement Implantation Syndrome: A Report of Four Cases. Indian Journal of Anaesthesia. 2009;53(2):214-218.

[4] Timothy.J.Kaufmann, Mary.E.Jensen, Gabriele Ford, Lena.L.Gill, William.F.Marx, David.F. Kallmes, Cardiovascular Effects of Polymethylmethacrylate Use in Percutaneous Vertebroplasty. American Journal of Neuroradiology. 2002;23:601-604.

[5] Razuin.R, Effat.O, Shahidan.M.N, Shama.D.V, M.F.M Miswan. Bone Cement Implantation Syndrome. The Malaysian Journal of Pathology. 2013;35(1):87-90.

[6] Nikhil Mudgalkar, K.V.Ramesh. Bone Cement Implantation Syndrome: A Rare Catastrophe. Anesthesia: Essays and Researches. 2011;5(2):240-242.

[7] Satoshi Ono, Yoshinori Kadoma, Sadao Morita, Kazuo Takakuda, Development of New Bone Cement utilizing Low Toxicity Monomers. Journal of Medical and Dental Sciences, 2008;55:189-196.

[8] Joseph Eldor, Vladimir Kotlovker, Intralipid treatment: Is it only the tip of an iceberg? A new suggestion: Bone cement implantation syndrome (BCIS). Journal of Anesthesiology and Clinical Science. 2012;1:12.

[9] M.Hayakawa, Y.Fujioka, Y.Morimoto, A.Okamura, O.Kemmotsu, Pathological Evaluation of Venous Emboli During Total Hip Arthroplasty. Anaesthesia. 2001;56:571-575.

[10] Hugh Phillips, Peter.V.Cole, Alan.W.F.Lettin, Cardiovascular Effects of Implanted Acrylic Bone Cement. British Medical Journal. 1971;3:460-461.

[11] Orsini EC, Byrick RJ, Mullen JB, Kay JC, Waddell JP. Cardiopulmonary function and pulmonary microemboli during arthroplasty using cemented or non-cemented components. The role of intramedullary pressure. The Journal of Bone \& Joint Surgery. 1987;69:822-832.

[12] Byrick RJ. Cement implantation syndrome: a time limited embolic phenomenon. Canadian Journal of Anesthesia. 1997;44:107-111.

[13] Orsini EC, Richards RR, Mullen JM. Fatal fat embolism during cemented total knee arthroplasty: a case report. Canadian Journal of Anesthesia. 1986;29:385-386.

[14] Byrick RJ, Forbes D,Waddell JP. A monitored cardiovascular collapse during cemented total knee replacement. Anesthesiology. 1986;65:213-6.

[15] Byrick RJ, Bell RS, Kay JC, Waddell JP, Mullen JB. High-volume, high-pressure pulsatile lavage during cemented arthroplasty. The Journal of Bone \& Joint Surgery. 1989;71:1331-1336.

[16] Pennsylvania Patients Safety reporting system. PA-PSRS Patient Safety Advisory. 2006;3:1-8. 